\title{
Anionic Indicators on the Surface of Submicrospheres Consisting of Ionic Palladium(II) Complex
}

\author{
Cho Rong Kim, Tae Hwan Noh, Kyung Ho Yoo, Bok Ryul Yoo, $+{ }^{+}$and Ok-Sang Jung \\ Deparment of Chemistry, Pusan National Lniversity, Pusan 609-735, Korea. ${ }^{*}$ E-mall oksingatapan.ac.kr \\ Korea Institute of Science and Technologv, Seoul $130-650$. Korea \\ Received September 11, 2009, Accepted October 6, 2009
}

\begin{abstract}
Ionic palladium(II) complex, $\left[\left(\mathrm{Me}_{4} \mathrm{en}\right) \mathrm{Pd}(\mathrm{L})\right]_{2}\left(\mathrm{ClO}_{4}\right)_{4}\left(\mathrm{Me}_{4} \mathrm{en}=\mathrm{K}, \mathrm{X}, \mathrm{N}, \mathrm{N}\right.$ '-tetramethylethylenediamine; $\mathrm{L}=$ bis(4-(4-pyridylcarboxyl)pheny] methane), allows to fom a monodisperse submicrosphere without any template or additive. Surface-perchlorates on the submicrosphere have been exchanged by anionic $\mathrm{pH}$ indicators such as thymol blue, bronothy'nol blue, and bronocresol green. The ionic and amphiphilic properties of the palladium(II) complex appear to be primarily associated with the fomation and easy surface-anion exchange of submicrosphere. The surface-anion exchange through the electrostatic interaction is a very good tool for the surface-modification. The color of the $\mathrm{pH}$ indicator-exchanged submicrospheres is very sensitive to $\mathrm{pH}$ and $\mathrm{Hg}^{2+}$ cation, and thus they are promising to submicrospherical indicators.
\end{abstract}

Key Words: Amphiphilic properties. Ionic palladium(II) complex, Submicrosphere. Surface modification

\section{Introduction}

The formation and modification of uniform morphology by means of chemical triggers is an important field in the development of functional molecular materials. ${ }^{1-5}$ The surface-modification of submicrospheres via either the formation of core-shell or the change of external condition ${ }^{6}$ has been utilized in the formation of task-specific materials such as catalysts. electronic devices, drug-delivery medicines. ceranics. pigments, molecular recognizers decicants and cosmetics. ${ }^{41}$ Facile methods for the formation of submicrospheres based on metal chalcogenides have been developed wia steric effects. surface tension. electric and magnetic forces. permanent dipoles van der Waals interaction, hydrophilic interactions as well as the reaction parameters such as temperature. $\mathrm{pH}$. concentration. and reaction time. ${ }^{12.18}$ but formation of submicrospheres using designed ionic metal complexes as molecular building blocks is very rare except our previous papers. ${ }^{5.19}$ To our best knowledge, the surfaceanion exchange on submicrospheres by anionic $\mathrm{pH}$ indicators is unprecedented

Thus. in this report, the formation and surface-modification of submicrospheres of ionic palladium(II) complex have been explored. Formation of submicrospheres was carried out by the reaction of $\left(\mathrm{Me}_{4} \mathrm{en}\right) \mathrm{Pd}\left(\mathrm{ClO}_{4}\right)_{2}\left(\mathrm{Me}_{4}\right.$ en $=\mathrm{N}_{\mathrm{N}} \mathrm{N}^{\prime} \mathrm{N}^{\prime}$-tetramethỵ lethỵlenediamine) with bis(4-(4-pyridylcarboxyl)phenyl) methane (L). Anion exchange of perchlorates on the surface of submicrosphere with anionic indicators was accomplished. The $\mathrm{pH}$ indicator-exchanged submicrospheres were tested for potential $\mathrm{pH}$ indicators or specific ion sensors.

\section{Experimental}

Materials and Measurements. All chemicals including potassium tetrachloropalladate(II) and N.N. 'tetramethylethylenediamine (Me+en) were purchased from Aldrich Chemicals and used without further purification. Elemental micro- analyses (C. H. N) were performed on cry stalline samples by the Pusan Center at KBSI using a Vario-EL III. ${ }^{1} \mathrm{H}$ and ${ }^{13} \mathrm{C}$ NMR spectra were recorded on a Varian Mercury Plus 300 operating at 300.00 and $75 \mathrm{MHz}$, respectively, and the chemical shifts were relative to the intemal $\mathrm{Me}_{4} \mathrm{Si}$. Infrared spectra were obtained on a Nicolet 380 FTIR spectrophotometer with samples prepared as $\mathrm{KBr}$ pellets. Thermal analyses were carried out under a dinitrogen atmosphere at a scan rate of $10^{\circ} \mathrm{C} / \mathrm{min}$ using a Labsys TGA-DSC 1600. Mass spectrometric analysis was performed in methanol by KMS-700 Mstation Mass Spectrometer (Jeol, Japan) using a MS-MP9020D data system. Scauling electron microscope images were obtained on a JEM 2011.

Bis(4-(4-pyridylcarboxyl)phenyl)methane (L). Triethylamine (12.265 $\mathrm{mL} .88 \mathrm{~nm}$ nl) was added to a stirred mixture of bis(4hydroxy phenyl)methane (4.0048 g. $20 \mathrm{mmol}$ ) and isonicotinoyl chloride hydrochloride $(7.1208 \mathrm{~g}, 40 \mathrm{~nm}$ ol) in cliloroform $(200 \mathrm{~mL})$ at room temperature. The reaction mixture was refluxed for $+\mathrm{h}$. The solution was filtered. and then the filtrate was washed with aqueous solution of $0.5 \mathrm{~N} \mathrm{NaOH}$ and water several times. The chloroform layer was dried using magnesium sulfate and filtered. Evaporation of the chloroform gave a white product. The product was finally recrystallized in a solvent pair of chloroform and $n$-hexane, gave colorless needle-like crystals.

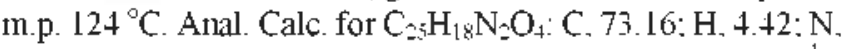
$6.83 \%$. Found: C. $72.30: \mathrm{H}, 4.45: \mathrm{N}, 6.69 \%$. IR $\left(\mathrm{KBr}, \mathrm{cm}^{-1}\right)$ : 2912.1741, 1502.1411. 1274, 1191. 1091. 'H NMR (Me_SO$\left.d_{6} \mathrm{SiMe}_{4} \delta \delta\right) 8.88(\mathrm{~d}, J=5.1 \mathrm{~Hz}, 4 \mathrm{H}), 8.00(\mathrm{~d}, J=5.1 \mathrm{~Hz}, 4 \mathrm{H})$, $7.37(\mathrm{~d}, J=8.4 \mathrm{~Hz},+\mathrm{H}) .7 .27(\mathrm{~d} . J=8.4 \mathrm{~Hz} .+\mathrm{H}), 4.04(\mathrm{~s} .2 \mathrm{H})$.

$\left[\left(\mathrm{Me}_{4} \mathrm{en}\right) \mathrm{Pd}(\mathrm{L})\right]_{2}\left(\mathrm{ClO}_{4}\right)_{4} \mathrm{~L}(0.1 \mathrm{mmol})$ in $10 \mathrm{~mL}$ of acetone was added slowly to $\left(\mathrm{Me}_{4}\right.$ en $) \mathrm{Pd}\left(\mathrm{ClO}_{4}\right)_{2}(0.1 \mathrm{nmmol})$ in $10 \mathrm{~mL}$ of distilled water. The mixture was refluxed for $2 \mathrm{l}$, and evaporation of acetone at ambient temperature gave a white subnicrospherical product of $\left[\left(\mathrm{Me}_{4} \text { en }\right) \mathrm{Pd}(\mathrm{L})\right]_{2}\left(\mathrm{ClO}_{4}\right)_{4}$. m.p. 236 $238^{\circ} \mathrm{C}$ (dec). Anal. Calc for $\mathrm{C}_{62} \mathrm{H}_{68} \mathrm{~N}_{8} \mathrm{O}_{24} \mathrm{Cl}_{4} \mathrm{Pd}_{2}$ : C. 44.75: $\mathrm{H}$, 4.12: N. $6.73 \%$. Found: C. 43.0; H, 4. 10; N, 6.69\%. IR (KBr, $\mathrm{cm}^{-1}$ ) 1747 (s. v(CO)), 1099 (br, v( $\left.\left(\mathrm{ClO}_{4}\right)\right), 623\left(\mathrm{v}\left(\mathrm{ClO}_{4}\right)\right) .{ }^{\mathrm{j}} \mathrm{H}$ 
NMR (Me $\left.2 \mathrm{SO}-d_{\kappa} \mathrm{SiMe}_{4}, \delta\right) 9.49(\mathrm{~m}, 4 \mathrm{H}) .9 .44(\mathrm{~d}, J=6.3 \mathrm{~Hz}$, $+\mathrm{H}) .8 .3 \mathrm{l}(\mathrm{m}, 4 \mathrm{H}) .8 .25(\mathrm{~d}, J=6.3 \mathrm{~Hz}, 4 \mathrm{H}) .7 .36-7.17(\mathrm{~m}, 4 \mathrm{H})$, $4.01(\mathrm{~s} .2 \mathrm{H}) .3 .00(\mathrm{~s} . \mathrm{H}) .2 .6 \mathrm{~L}(\mathrm{~s} .12 \mathrm{H})$, dissociated ligand $=8.87$ (s). 7.99 (s). $7.36-7.17$ (m), 3.90 (s. $2 \mathrm{H}$ ). FAB Mass: $m / z 1563$ $\left[\mathrm{M}-\mathrm{ClO}_{4}\right]^{-}, 1156\left[\mathrm{M}-\mathrm{Me}_{4} \text { en-ClO }-\left(\mathrm{HClO}_{4}\right)_{3}\right]^{+}, 1036\left[\mathrm{M}-2\left(\mathrm{Me}_{4} \mathrm{en}\right)-\right.$ $\left.\mathrm{ClO}_{4} \cdot\left(\mathrm{HClO}_{4}\right)_{3}\right]^{-}$.

Anion Exchange of Perchlorates on the Surface of Submicmsphere with Anionic Indicators. An aqueous suspension of the submicrospheres $(0.03 \mathrm{mmol})$ was mixed with the aqueous solution of anionic $\mathrm{pH}$ indicators (bromocresol green: $\mathrm{NaC}_{21}$ $\mathrm{H}_{1} \leqslant \mathrm{Br}_{4} \mathrm{O}_{5} \mathrm{~S}$ : bromothymol blue: $\mathrm{NaC}_{2}-\mathrm{H}_{2} \mathrm{Br}_{2} \mathrm{O}_{5} \mathrm{~S}$; thymol blue: $\left.\mathrm{NaC}_{Y 7} \mathrm{H}_{31} \mathrm{O}_{5} \mathrm{~S}\right)(0.05 \mathrm{mmol})$. The mixture was sonicated for 20 min to obtain the indicator-exchanged submicrospheres. The $\mathrm{pH}$ indicator-exchanged products were washed with water three times to eliminate unchanged indicators.

\section{Results and Discussion}

Slow evaporation of acetone of $\left[\left(\mathrm{Me}_{4} e n\right) \mathrm{Pd}(\mathrm{L})\right]_{3}\left(\mathrm{ClO}_{4}\right)_{4}$ in a mixture of acetone and water ( $1: 1)$ produces submicrospheres in high yield as shown in Scheme 1 . The size of submicrospheres are unifonm $(\sim 400 \mathrm{~nm})$. The chemical structure was characterized by elemental analysis, ${ }^{1} \mathrm{H}$ NMR. IR $\left(v\left(\mathrm{ClO}_{4}^{-}\right)\right.$at $\left.1088 \mathrm{~cm}^{-3}\right)$, thermal analy ses and mass spectrometry and the morphology was identified by SEM images. The $\left[\left(\mathrm{Me}_{4} e_{n}\right) \mathrm{Pd}(\mathrm{L})\right]_{2}\left(\mathrm{ClO}_{4}\right)_{4}$ was attempted to take ${ }^{\mathrm{l}} \mathrm{H} \mathrm{NMR}$ spectnim in $\mathrm{Me} \mathrm{SO}_{2} \mathrm{SO} d_{6}$. but the complex was dissociated in the solution (Supporting Information). Anyway. the NMR spectrum does not show any proton peak except for $\mathrm{L}$ and Me+en. indicating that the solid complex is pure enough. The mass data were obtained in order to characterize the molecular weight of the palladium(II) complex. The mass peaks $\left(m / z=1563,\left[\mathrm{M}-\mathrm{ClO}_{4}\right]^{+}\right)$and isotope ratio indicate that the submicrosphere consists of cyclodimeric molecules (Supporting Infonnation). The part around palladium(II) cations and $\mathrm{ClO}_{4}^{-}$counteranions seems to be hydrophilic. and L moiety seems to be relatively hydrophobic. The submicrospheres are hardly soluble in water or acetone. but are slightly soluble in a mixture of water and acetone. This solubility indicates that the palladium(II) complex is amphiphilic. Of course. the submicrospheres were not formed without water as a me-

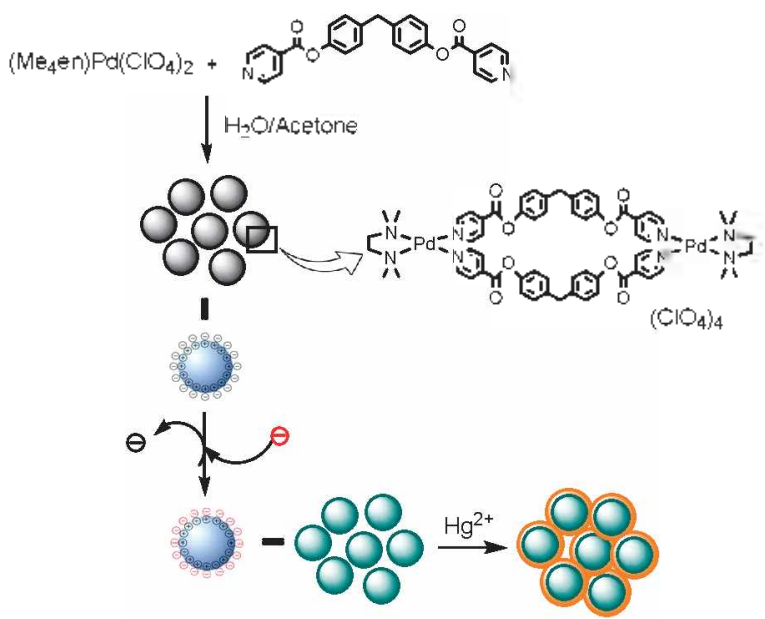

Scheme 1 (a)

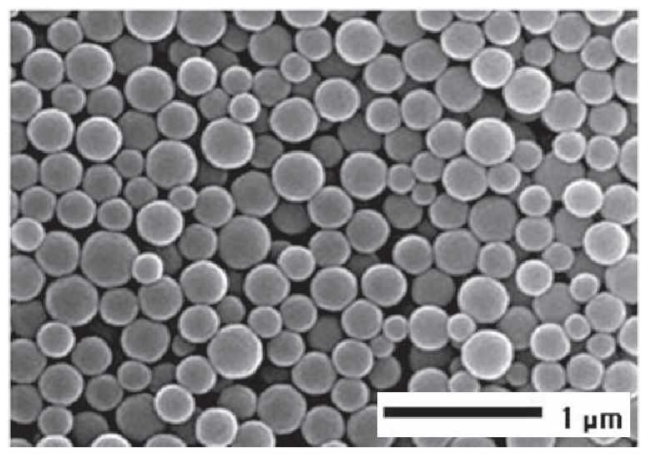

(b)

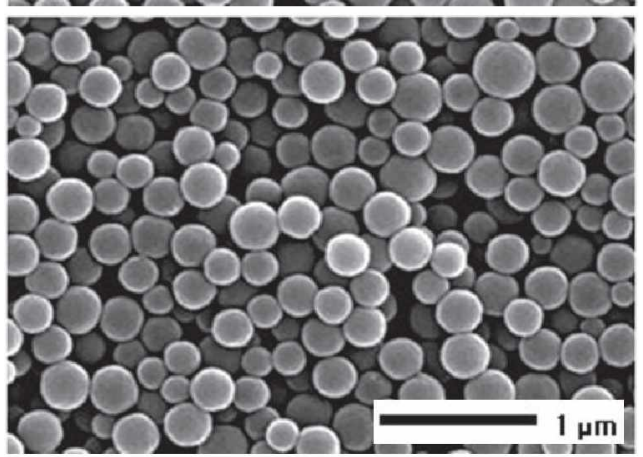

(c)

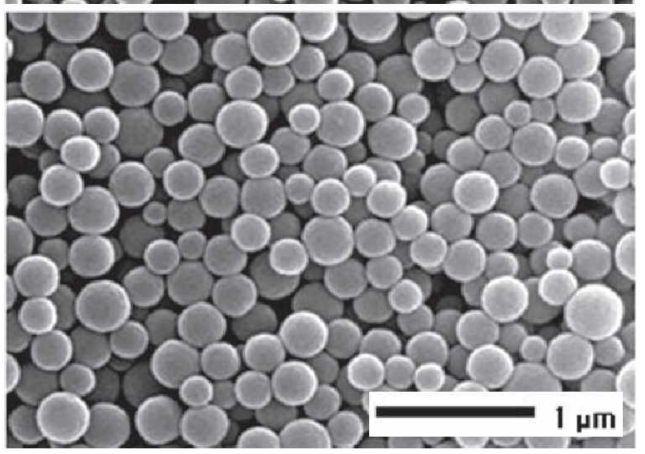

Figure 1. SEM inages of $\mathrm{pH}$ indicator-exchanged submicrosphere. Bromothymol blue (a), thymol blue (b), and bromocresol green (c).

(a)

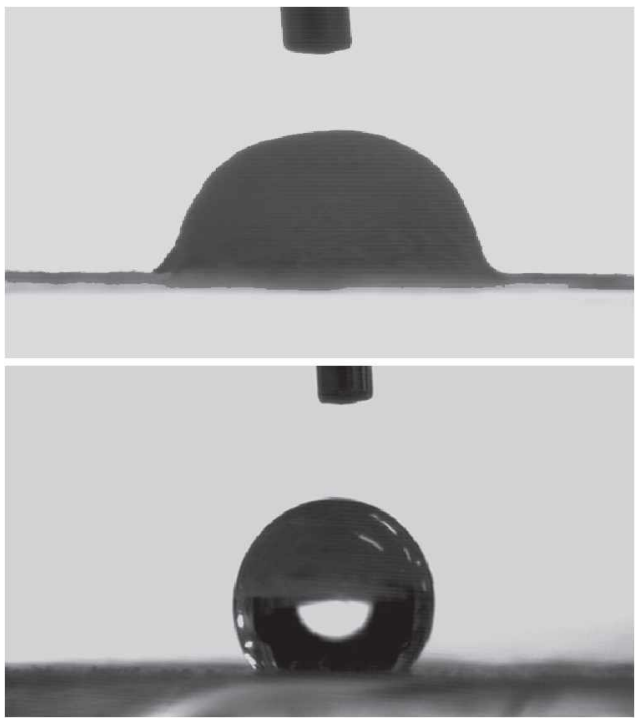

Figure 2. Contact angle of a water-droplet on the monolaver of submicrosphere (a) and indicator (bromocresol green)-exchanged sphere (b). 
(a)

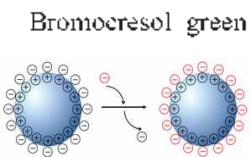

(b)

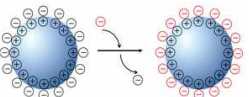

(c)

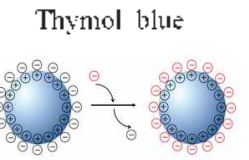

Bromothymol bluc
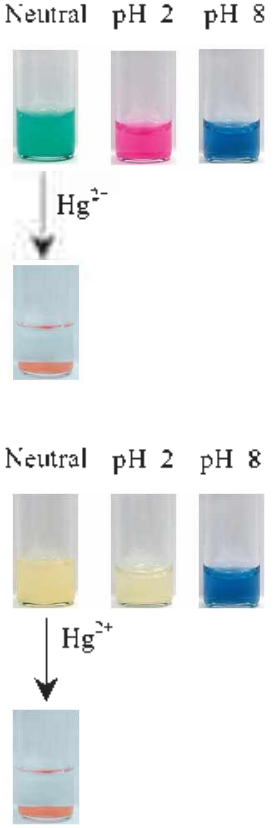

Neutral $\mathrm{pH} 2 \mathrm{pH} 8$
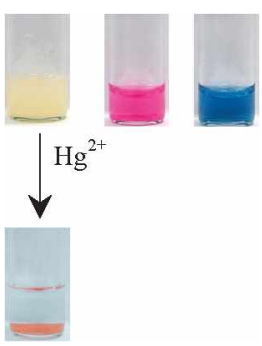

Figure 3. The color change of $\mathrm{pH}$ indicator-exchanged submicrosphere depending on $\mathrm{pH}$ and in the presence of $\mathrm{Hg}^{2+}$ in water. Bromothymol blue (a), thymol blue (b), and bromocresol green (c).

diator. The microspherical materials are thermally stable up to $236^{\circ} \mathrm{C}$

Anion exchange of $\mathrm{ClO}_{4}{ }^{-}$anions on the surface of submicrospheres with anionic $\mathrm{pH}$ indicators in aqueous suspension was smoothly accomplished via sonication. The size and shape of $\mathrm{pH}$ indicator-exchanged submicrospheres were preserved (Figure 1). The $\mathrm{pH}$ indicator-exchanged submicrospheres were characterized by IR and the contact angles of a water-droplet. The intensity of $v\left(\mathrm{ClO}_{4}\right)$ at $1088 \mathrm{~cm}^{-3}$ slightly decreases. indicating that the surface-perchlorate anions are exchanged by anionic $\mathrm{pH}$ indicators(bromocresol green, bromothy mol blue. and thymol blue). The surface-wettability of the indicatorexchanged submicrosphere is very different from that of the original submicrospheres. In order to quantify the information on the surface wettability. their contact angles $s^{3,5}$ of a drop of water on the layer of submicrospheres were measured (Figure 2). The contact angles of the $\mathrm{pH}$ indicator-exchanged submicrospheres $\left(115.5^{\circ}\right)$ showed much higher than those of the original submicrospheres $\left(33.5^{\circ}\right)$. indicating that the surface of the $\mathrm{pH}$ indicator-exchanged submicrospheres are much more hydro (a)

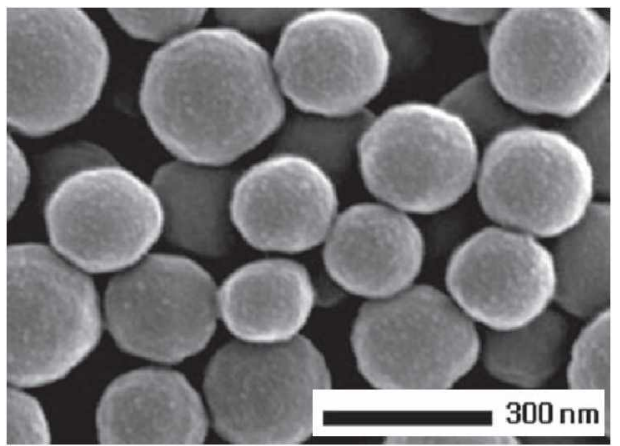

(b)

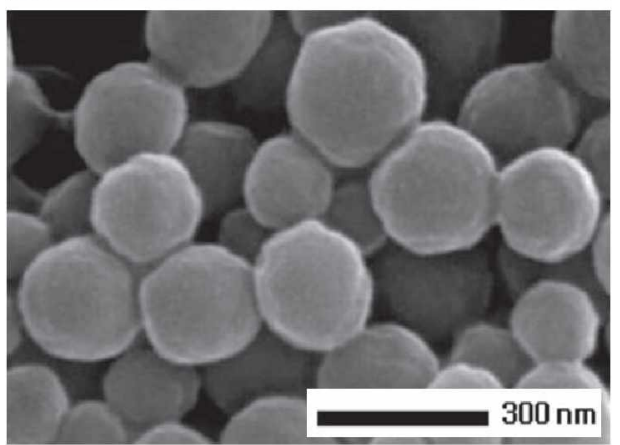

(c)

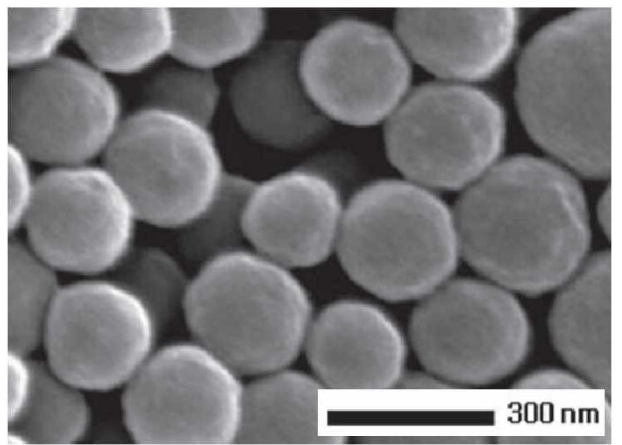

Figure 4. SEM inages after interaction of the indicator-exchanged submicrospheres with $\mathrm{Hg}\left(\mathrm{NO}_{3}\right)_{2}$ species in aqueous solution. Bromothy mol blue (a), thymol blue (b), and bromocresol green (c).

phobic. The $\mathrm{pH}$ indicator-exchanged subnicrospheres were also characterized by EDX (Supporting Information). The size of the exchanged submicrospheres is very sinilar to the original spheres. implying that the indicator is simply exchanged on the surface in a molecular level. The surface of the $\mathrm{pH}$ indicator-exchanged submicrosphere is slightly rougher than that of the original submicrosphere. From the EDX results of the indicator-exchanged submicrosphere and the original submicrosphere. the exchanged submicrospheres are significantly containing $\mathrm{S}$ and $\mathrm{Br}$ (thymol blue. brontocresol green) elentents. suggesting that the $\mathrm{ClO}_{4}^{-}$counteranions are exchanged by each anionic indicator. Thus the quantity of $\mathrm{Cl}$ decreases. The anionic $\mathrm{pH}$ indicators on the exchanged submicrospheres were not easily dissociated in aqueous media, presumably owing to the presence of electrostatic interactions between anionic indicators and cationic palladium(II) ${ }^{19}$ on the surface of submicrospheres consisting of ionic palladium(II) complexes. This process is an advanced method for the surface-modification of submicrospheres. The ionic characters of the complex seem to be an important factor in the formation of anion exchange. The color 
of the indicator-exchanged submicrospheres is, of course. very sensitive to $\mathrm{pH}$ in aqueous solution and will be explained in detail.

In order to test the ability of $\mathrm{pH}$ indicator. the color change of the indicator-exchanged submicrospheres was carried out in aqueous suspension. Both the submicrospheres on the plate and the submicrospheres in aqueous suspension are very sensitive to $\mathrm{pH}$, which are similar to the litmus paper (Figure 3 ). Furthermore, the color of the indicator-exchanged submicrospheres changes by the presence of $\mathrm{Hg}\left(\mathrm{NO}_{3}\right)_{2}$ species in aqueous solution. For instance. bromothymol blue and thymol blueexchanged submicrospheres change from yellow to yellowish red. Bromocresol green-exchanged submicrospheres change from green to yellowish red in the aqueous solution (Figure 3 ). These facts are reproducible in the presence of trace mercury(II) ions. The color-changed submicrospheres were slightly rough and were relatively conglomerated as depicted in Figure 4. The anionic $\mathrm{pH}$ indicators on the surface seem to partly react with $\mathrm{Hg}^{2+}$ cation on the surface. The reation of $\mathrm{Hg}\left(\mathrm{NO}_{3}\right)_{2}$ with the indicators produces the similar color solids. The structure of the $\mathrm{pH}$ indicators plays an important role in the detection of $\mathrm{Hg}^{2+}$ ion on the surface of submicrospheres. Number of bromine of the indicators may be affected for the detection. The quantity of $\mathrm{Hg}^{2+}$ ion on the submicrospheres is in the order of thymol blue $>$ bromothymol blue ( 2 bromines) $>$ bromocresol green ( + bromines) (see the EDX results of Supplementary material). Even though the reaction solution is acidic ( $\mathrm{pH}=-2.0$ ). indicating that $\mathrm{Hg}^{3+}$ interact with the surface-anions of submicrosphere rather than acidic species.

\section{Conclusion}

The assembly of amphiphilic ionic palladium(II) complexes with a new bidentate ligand in a mixthure of water and acetone was proved to be an efficient strategy for the formation of submicrospheres without the addition of any templates. In particular. the anion exchange on the surface through the electrostatic interaction is a very good tool for the surface-modification. To our best knowledge. this report is the first suspension $\mathrm{pH}$ indicator. which is a basis for sensing some toxic chemicals.
The surface-modification of sphere nay be useful to clinical diagnosis. catalysis and the transport of dnugs or proteins.

Aclonowledgments. This research was supported by a grant from the Fundamental R\&D Program for Core Technology of Materials funded by the Ministry of Knowledge Econony, Republic of Korea.

\section{Refeiences}

1. Busch, S.; Dollaine, H.; DuChesne, A.: Heinz, S.: Hochrein, O.; Laeri, F.; Podebrad, O.: Vietze, U.: Weiland, T.: Knief. R. Eur. $J$. Ihorg. Chem. 1999, 643.

2. Marn, S. Angew: Chent, Int. Ed. 2000, 39, 3392.

3. Yoon, H. T.; Chun, I. S.: Na, Y. M.; Lee, Y.-A.: Tung, O.-S. Chem. Commm. 2007, 492 .

4. Chun, I. S.; Kwon, I. A.: Yoon, H. J.: Bae, M. N.; Hong, J.: Jung, O.-S. Angew. Chem., Int. Ed. 2007, 46, 4960 .

5. Chun, I. S.; Lee, K. S.; Hong, T.; Do, Y.; Jung, O.S. Chem. Lett. $2007,36,584$

6. Manna, L.: Scher, E. C.: Alivisatos, A. P. J. Am. Chem. Soc. 2000, 122.12700

7. Caruso, F.; Caruso, R. A.; Mohwald, H. Science 1998, 282, 1111.

8. Decher, G. Science 1997, 277, 1232

9. Sun, S.; Murray, C. B.; Weller, D.; Folks, L.; Moster, A. Science? $2000,287,1989$

10. Dibben, E. M.; Toublan, K. F. I. I.: Suslick, S. J. Am Chem. Soc. $2006,128,6540$

11. Jeong, U.; Herricks, T.; Shahar, E.; Xia, Y. J. Ant. Chent. Soc. 2005, 127,1098 .

12. Bowden, N.; Terfort, A.: Carbeck, J.: Whitesides, G. M. Science $1997,276,233$

13. Gracias, H.: Tien, J.: Breen, T. L.: Hsu, C.: Whitesides, G. M. Science 2000, 289, 1170 .

14. Whitesides, G. M.; Grzybowski, B. Science 2002, 295, 2418

15. Thalladi, V. R.; Whitesides, G. M. J. Am. Chem. Soc. 2002, 12t, 3520

17. Whang. D.: Tin. S: Wu, Y.: Lieber. C. M. Nano. Lett. 2003, 3. 1255.

18. Dinsmore, A. D.; Hsu, M. F.; Nikolaides, M. G.; Marquez, M.; Bausch, A. R.: Weitz, D. A. Science 2002, 298, 1006.

19. Yoon, H. J.: Chun, I. S.: Kim, J. P.; Lee, Y. S.; Jung, O.-S. Hater. Lett. 2008, 62, 2883. 